Case Report

\title{
New Treatment for Urethral Rent in Stallions
}

\author{
Yame Fabres Robaina Sancler-Silva a, *, Edjalma R. Silva-Junior ${ }^{\text {a }}$, Carleigh E. Fedorka ${ }^{\text {, }}$ \\ Veronica F.C. Scheeren ${ }^{a}$, Thais S. Cavalero a, Patricia M. Papa a, Marco A. Alvarenga a, \\ Jose A. Dell'Aqua Jr. ${ }^{a}$, Frederico O. Papa ${ }^{\text {a }}$
}

${ }^{a}$ School of Veterinary Medicine and Animal Science, Sao Paulo State University (UNESP), Botucatu, Sao Paulo, Brazil

${ }^{\mathrm{b}}$ Maxwell H. Gluck Equine Research Center, Department of Veterinary Science, University of Kentucky, Lexington, KY

\section{A R T I C L E I N F O}

\section{Article history:}

Received 24 November 2017

Received in revised form

6 February 2018

Accepted 6 February 2018

Available online 20 February 2018

\section{Keywords:}

Hemospermia

Chemical cauterization

Equine

Semen

Artificial insemination

\begin{abstract}
A B S T R A C T
The aim of this report is to describe a new methodology to successfully treat stallions diagnosed with urethral rent. Four stallions of ages ranging from 7 to 12 years (median 9) with hemospermia were admitted for clinical evaluation, breeding soundness examination, and urethroscopy for inspection of the urethra and vesicular glands. Once the presence of urethral rent was identified and/or other sources of hemorrhage were excluded, a topical treatment was performed with $4 \%$ Policresulen solution (Albocresil). The treatment was carried out by infusing $100 \mathrm{~mL}$ of the solution into the lumen of the urethra through a catheter placed up to the region of the ischial arch. This procedure was repeated once daily, or at 48 hours intervals, resulting in a total of 4-7 infusions. In all cases, chemical cauterization was efficient in the healing of the urethral rent. However, due to masturbation during treatment, one animal did not completely heal, and the treatment with the Policresulen was prolonged. It is believed that the low $\mathrm{pH}$ of the solution resulted in urethritis, which was treated with systemic therapy of antibiotic and anti-inflammatory nonsteroidal. Topical treatment with $4 \%$ Policresulen was found to be efficient in the chemical cauterization of urethral rent in stallions. This treatment was efficient, practical, less invasive, and less costly than the alternative of surgical methods, which are more invasive and require longer recovery time of the animal. However, sexual rest and the elimination of sexual stimuli from the environment are essential management in association with this therapeutic method.
\end{abstract}

(C) 2018 Elsevier Inc. All rights reserved.

\section{Introduction}

Urethral rents are lesions that extend from the surface of the urethra to the corpus spongiosum of the penis, leading to hemospermia in stallions $[1,2]$. They usually occur in any age or breed and commonly occur on the convex surface of the ischial segment of the urethra and are longitudinally oriented [1,3]. Diagnosis is based on the identification of blood in the ejaculate, followed by visualization of urethral rent by urethroscopy [4]. However, it is not always possible to identify the exact location of the lesion, as sedation is administered for examination, and the penis presents in a relaxed

\footnotetext{
Animal welfare/ethical statement: This study was evaluated and approved by the Ethics Committee from the referred institution, under protocol CEUA81/2015.

Conflict of interest statement: The authors declare that there is no conflict of interest.

* Corresponding author at: Yame Fabres Robaina Sancler-Silva, School of Veterinary Medicine and Animal Science, Sao Paulo State University (UNESP), Botucatu 18610-970, Sao Paulo, Brazil.

E-mail address: yamefabres@gmail.com (Y.F.R. Sancler-Silva).
}

state, removing the conditions that favor bleeding during the time of copulation [5]. Due to this, much of diagnostics involve the elimination of other causes of bleeding, such as seminal vesiculitis [6,7], several penile lesions (trauma, squamous cell carcinoma, infection, and habronemiasis) [8-10], and midline cysts of the colliculus seminalis [11].

The cause of urethral rent still remains unknown; however, some theories have been hypothesized. It is believed that the reason for urethral rents to be more common in the ischial region is an abrupt reduction of a diameter of the urethra at this site, resulting in an increased hydrodynamic force during erection and ejaculation [3]. Also, during sexual stimulation, blood flows into the corpus spongiosum increasing its diameter, which is followed by rhythmic contractions of the bulbospongiosus muscle that surround the urethra leading to ejaculation $[5,12]$. The combination of these events results in 45 -fold increase of pressure within the corpus spongiosum, favoring the onset of this lesion at the ischial arch of the urethra [12].

The urethral rents cause extravasation of blood into urethral lumen during breeding, leading to hemospermia [13,14]. The semen 
contaminated with blood has a devastating effect on equine fertility $[8,15,16]$, resulting in sterility when the blood volume accounts for $50 \%$ of the total volume of the ejaculate [17].

There are few reports in the literature of urethral defects in stallions, most of which were treated by surgical procedures $[8,18]$. The most common surgical technique is that of the temporary subischial incision, where an incision is made from the skin of the perineal region to the corpus spongiosum of urethra. This procedure results in a decompression of the corpus spongiosum and diversion of the blood flow to the external environment instead of the urethral lumen, allowing healing of the fistula by second intention [1]. Another technique uses laser cauterization of the fistula, which is less traumatic. However, this technique requires the exact identification of the lesion site, which makes it impracticable in several patients [19]. In all cases, therapeutic techniques should be associated with supportive therapy and sexual rest of the stallion [18].

Thus, the aim of this manuscript is to report on cases of urethral rent in stallions that were successfully treated with chemical cauterization using topical Policresulen solution. Introduction of this unique, effective, and minimally invasive treatment of the urethral rents in stallions would be of great value, considering the impact of hemospermia on equine fertility.

\section{Material and Methods}

Animals were selected for this study after admission to the College of Veterinary Medicine and Animal Science from Sao Paulo State University, Botucatu/SP-Brazil, due to a history of moderate to severe hemospermia detected at the time of semen collection.

A physical examination was performed in all stallions, which included teasing utilizing a mare in estrus for the inspection of penis, urethral process, urethral fossa, and prepuce. The penis was also assessed for the presence of blood on the urethra at the time of teasing. Semen was then collected using a Botucatu artificial vagina model (Botupharma Ltda., Botucatu, SP, Brazil) and assessed for color, appearance, and volume. Sperm kinetics were evaluated by computer-assisted semen analysis (Hamilton Thorne Research: HTM IVOS 12, Beverly, MA). Sperm concentration was evaluated using a Neubauer chamber, and the percentage and type of blood cells were assessed using microscopy, where 100 cells were counted in a cellular smear stained by Diff-Quick (Instant Prov-Newprov, Pinhais, PR, Brazil). The semen collection and laboratory analysis were repeated at least twice in all stallions evaluated.

Once the presence of red blood cells was detected in the ejaculate, an endoscopic examination was performed using a flexible video endoscope with a length of $3 \mathrm{~m}$ and a diameter of $9.8 \mathrm{~mm}$ (PortoScope PVS93M System: PortoScope, Orlando, FL). Before the examination, the animals were placed in stocks and sedated with $1 \mathrm{mg} / \mathrm{kg}$ of $10 \%$ xylazine hydrochloride and $0.1 \mathrm{mg} / \mathrm{kg}$ of $1 \%$ acepromazine maleate intravenously, aiming at chemical containment and penile exposure for at least 30 minutes. Once the penis was exposed, the glans penis, urethral process, and urethral fossa were cleaned with sterile saline solution. Then, the endoscopic probe was introduced into the penile urethra, which was dilated by air. The entire urethral mucosa was carefully inspected up to colliculus seminalis. At this site, a polypropylene sterile catheter was used to guide the entry of the ejaculatory ducts, accessing both seminal vesicles. The glandular lumen was filled by air, and the whole mucosa was examined for hemorrhage or any sign of infection.

Stallions diagnosed with a urethral rent were then administered the topical treatment with Policresulen, aiming for the chemical cauterization of the lesion. In those in which the lesion was not found, but all other sources of bleeding were discarded after examination, the treatment was also performed, considering a presumptive diagnosis of the urethral rent. The final diagnosis in these cases was confirmed, if the hemospermia was resolved after the treatment.

The cauterizing solution was prepared by diluting $4 \mathrm{~mL}$ of Policresulen (Albocresil-360 mg/g, Takeda Pharma Ltda, Jaguariuna, SP, Brazil) in $96 \mathrm{~mL}$ of distilled water to obtain a $4 \%$ solution. The stallions were then placed in stocks and sedated with $0.5 \mathrm{mg} /$ $\mathrm{kg}$ of $10 \%$ xylazine hydrochloride and $0.05 \mathrm{mg} / \mathrm{kg}$ of $1 \%$ acepromazine maleate intravenously for a brief tranquilization and induced penile exposure.

A flexible pipette $(75 \mathrm{~cm})$, used for deep uterine insemination (Minitube: Equine IUI Universal Pipette Ref. 17209/1175, Porto Alegre, RS, Brazil), was inserted into the urethral lumen up to the ischial arch region and then $100 \mathrm{~mL}$ of $4 \%$ Policresulen solution was infused (Fig. 1). During the procedure, manual pressure was applied at the base of the glans penis to restrict the solution to the urethral mucosa for 5 minutes. This treatment was repeated once a day or at 48 hours intervals, for a total of 4-7 infusions.

\section{Case Reports}

Case 1: A 12-year-old Quarter Horse stallion was admitted at our hospital with a history of hemospermia and decreased fertility beginning 3 months before admission. The animal was kept at sexual rest after this period, but blood remained within the ejaculate. In the hospital, clinical evaluation and inspection of the external genital tract (glans penis, penile body, urethra, urethral process, and prepuce) revealed no alterations. All semen collections resulted in urethral bleeding beginning during the excitation phase (Fig. 2A). On visual inspection of each ejaculate, severe hemospermia was identified (Fig. 2B), presenting as a bright red color with a total mean volume of $80 \mathrm{~mL}$ with milky consistency. The semen samples presented an average $\mathrm{pH}$ of 7.1 (Digital $\mathrm{pH}$ Meter Analion PM608, SP, Brazil) and osmolarity of $365 \mathrm{mOsm} / \mathrm{kg}$ (Automatic Digital Osmometer Osmette A, MA). Due to the predominance of red blood cells in the seminal sample, it was not possible to perform the spermatic kinetics analysis using the computer-assisted semen analysis (CASA) method. The ratio between blood cells and sperm in the in the semen smear indicated $92 \%$ red cells, $7 \%$ sperm and $1 \%$ leukocytes. After collection and analysis of the semen, endoscopic examination of the urethra and seminal vesicle was performed to establish the diagnosis. During the procedure, a pale-appearing linear area was visualized on the convex surface of the proximal urethra at the level of the ischial arch, which presented bleeding compatible with urethral rent (Fig. 3A and 3B). The right and left seminal vesicles were accessed, and no abnormality was observed. Once the diagnosis of urethral rent was established, topical treatment with $4 \%$ Policresulen and sexual rest for 1 week were instituted. The infusion of $100 \mathrm{~mL}$ of the solution via the flexible pipette was carried out once a day for 5 days. One week after the end of treatment, a new collection of semen was performed, and no bleeding was observed during the period of excitation. The semen presented as a white-gray coloration, aqueous aspect, total volume of $50 \mathrm{~mL}, \mathrm{pH}$ of 7.34, and osmolarity of $300 \mathrm{mOsm}$. The analysis of sperm kinetics by CASA method showed $80 \%$ of total motility, $44 \%$ of progressive motility, and $72 \%$ of rapid sperm. Seminal smear analysis revealed $98 \%$ sperm and 2\% leukocytes. A new urethroscopy was performed about 10 days after the end of treatment, and no abnormalities were found during the examination. In addition, the stallion did not present remission of the episodes of hemospermia.

Case 2: An 8-year-old Mangalarga Marchador stallion presented for hemospermia, which began 1 month before admission. The stallion sexually rested for 2 weeks, but after this period, mild blood contamination of the semen returned in the third collection. At the 


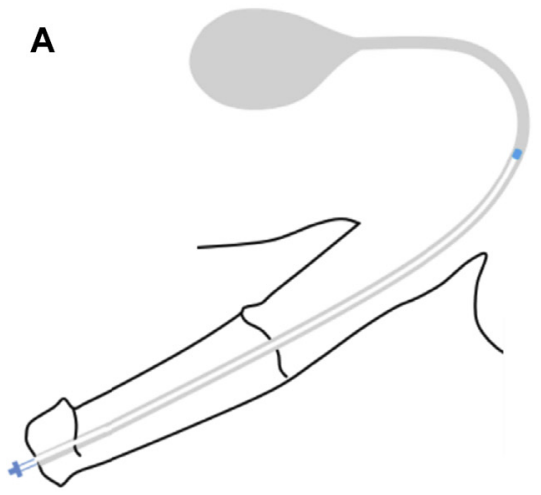

B

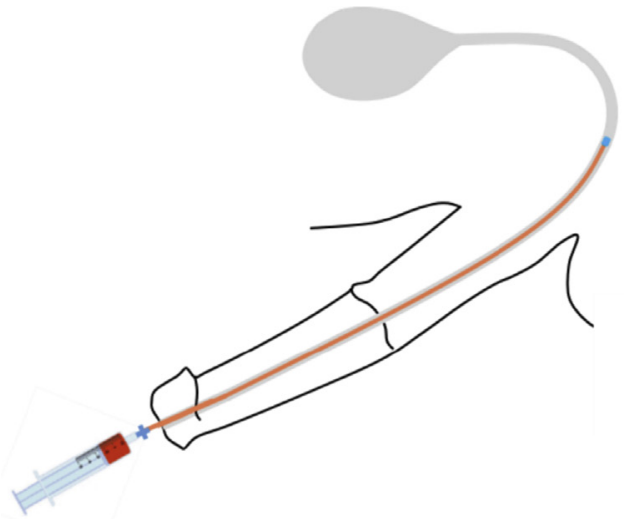

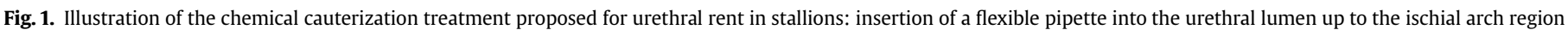
(A) followed by the infusion of $100 \mathrm{~mL}$ of $4 \%$ Policresulen solution (B).

hospital, three semen collections were performed. Clinical examination and inspection of the external genital tract did not identify any changes in glans penis, penile body, urethral process, or prepuce. Visual inspection of the ejaculate found moderate hemospermia, with pinky semen color, milky consistency, and total mean volume of $45 \mathrm{~mL}$ (Fig. 4A). The sample presented with a pH of 7.2 and osmolarity of $330 \mathrm{mOsm}$. Sperm kinetics was evaluated using the CASA method and found to have 55\% of total motility, $28 \%$ of progressive motility, and $30 \%$ of fast sperm. In the seminal smear, cellular consistency was found to be $25 \%$ red blood cells and $75 \%$ sperm (Fig. 4B). No abnormalities were identified during urethroscopy in the urethral mucosa as well as inside of the two vesicular glands. Thus, topical treatment with a $4 \%$ Policresulen solution was instituted in addition to sexual rest for 1 week. The infusion of $100 \mathrm{~mL}$ of the solution via the flexible pipette was carried out for 4 days with an interval of 24 hours between applications. One week from the end of last infusion a new semen collection was performed, and no blood contamination of the semen was observed.
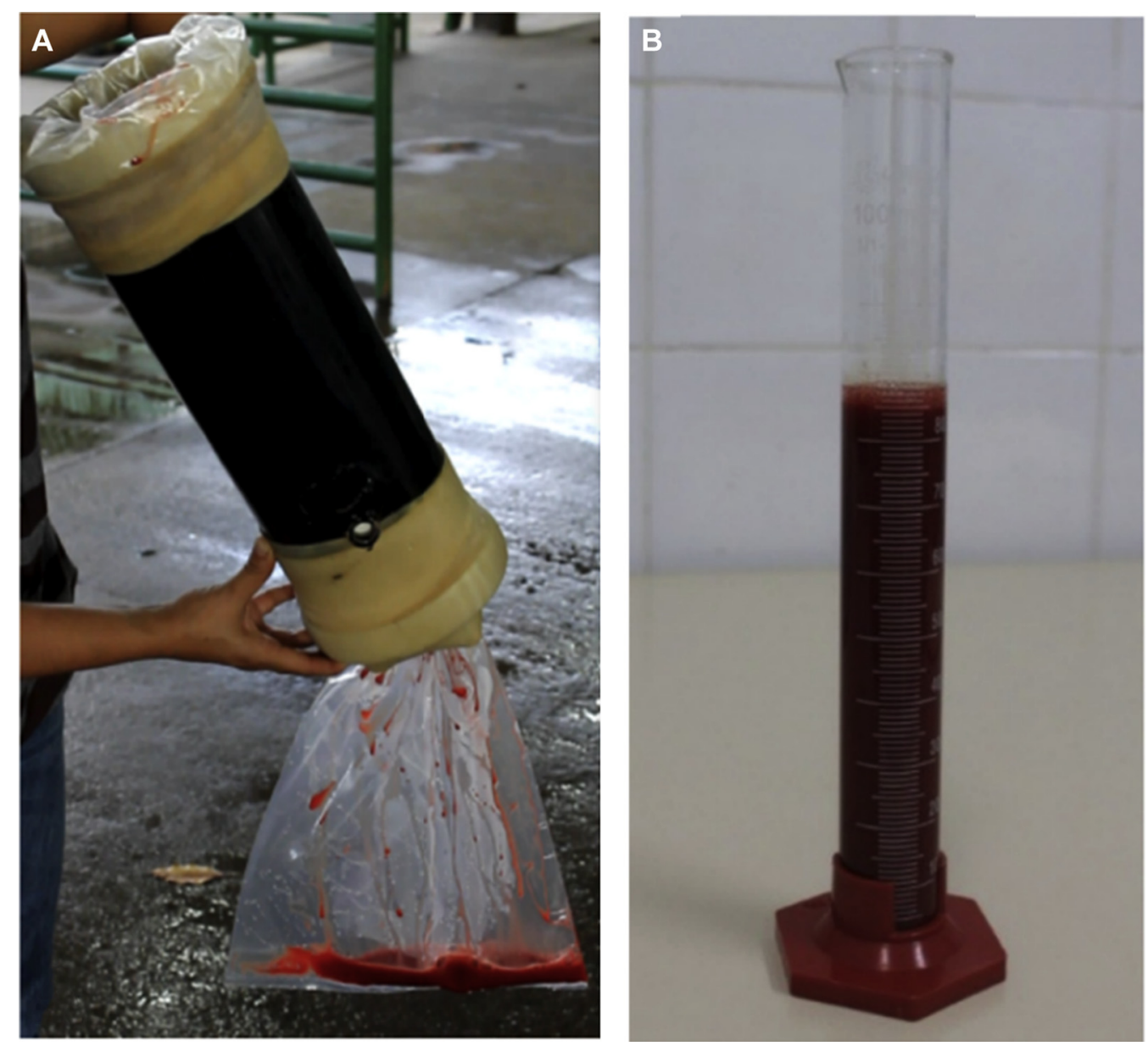

Fig. 2. Ejaculate collected presenting great amount of blood (A); Inspection of the ejaculate determining severe hemospermia (B). 

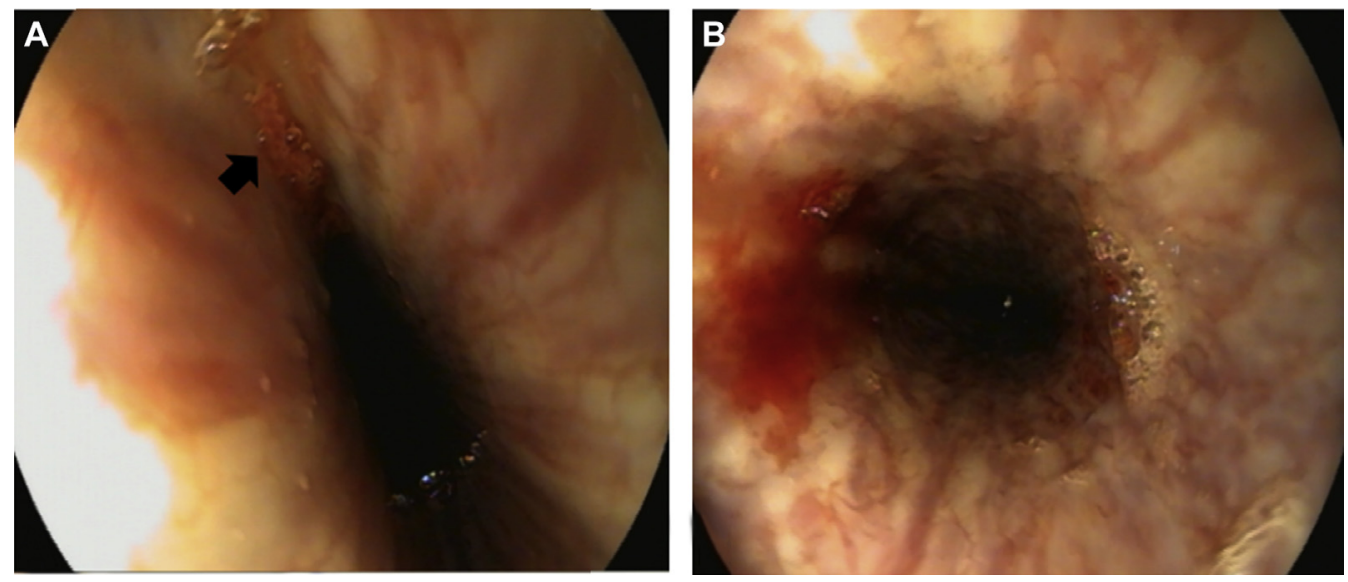

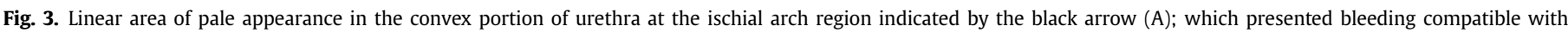
urethral rent (B).

The semen presented as a white-gray color, with aqueous consistency, total volume of $40 \mathrm{~mL}, \mathrm{pH}$ of 7.3 , and osmolarity of 320 mOsm. The total motility reached $78 \%$, the progressive motility $35 \%$, and the percentage of fast sperm was $40 \%$. No red blood cells were observed on the seminal smear analysis after treatment, and the animal did not present with hemospermia after treatment and was reintroduced into the artificial insemination program.

Case 3: A 7-year-old Lusitano stallion with hemospermia that was first observed 2 months before the admission was evaluated in the hospital to establish diagnosis and treatment. At the farm, the stallion was sexually rested for 30 days but continued presenting hemospermia on the following semen collections. During clinical examination, the stallion showed no systemic or external genital tract abnormalities. Two semen collections were performed, with the animal experiencing moderate hemospermia in both, with pink semen color (Fig. 5A). The first and second ejaculates presented total volume of 72 and $68 \mathrm{~mL}$, respectively. The CASA evaluation found $65 \%$ of totally motile sperm, $22 \%$ of progressive motility, and $26 \%$ of rapid sperm. The stained seminal smear evaluation revealed $36 \%$ of red blood cells and $64 \%$ of sperm. It was not possible to identify lesions compatible with urethral rent; however, as the diagnosis of seminal vesiculitis and midline cyst of the colliculus seminalis were discarded during urethroscopy and transrectal ultrasonography, a presumptive diagnosis of the urethral rent was stated. Thus, topical treatment with $4 \%$ Policresulen was initiated, and $100 \mathrm{~mL}$ of the solution was infused through flexible pipette up to the ischial arch region, remaining for 5 minutes in contact with the mucosa. This procedure was performed at 24 hours intervals for 4 days. During treatment, the animal was kept in an isolated bay and remained in sexual rest for 7 days. After this period, semen collection was performed, and semen was assessed to be a normal white-gray color, $50 \mathrm{~mL}$ of total volume (Fig. 5B), total motility of $82 \%$, progressive motility of $40 \%$, and percentage of rapid sperm of $46 \%$. In addition, a posttreatment seminal smear revealed the total absence of blood cells. The animal was reintroduced to the semen collection routine without representing hemospermia.

Case 4: A 10-year-old Mangalarga Marchador stallion presented with hemospermia and infertility for 1 year was admitted to the hospital. A clinical examination of the external genital tract presented no abnormalities. During the two semen collections within the clinic, bleeding was observed from the urethra during the excitation stage, and severe contamination of the semen with fresh blood occurred (Fig. 6A). Due to the population of erythrocytes reaching a prevalence of $70 \%$ compared with $30 \%$ sperm, it was not possible to evaluate the sperm kinetics. The urethroscopy showed the presence of a rent in the penile urethra, and seminal vesiculitis
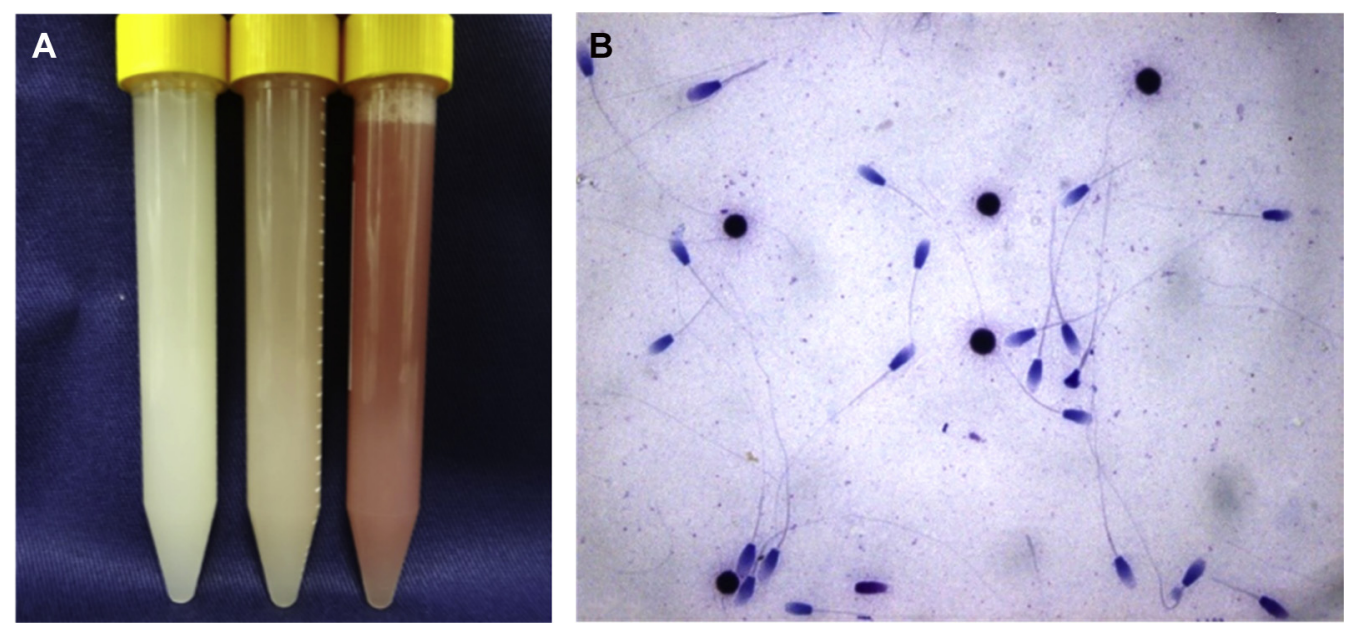

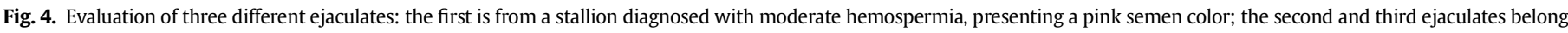
to healthy animals with white-gray and white semen color, respectively (A); seminal smear stained with Diff-Quick, presenting $25 \%$ of red blood cells and $75 \%$ of sperm (B). 

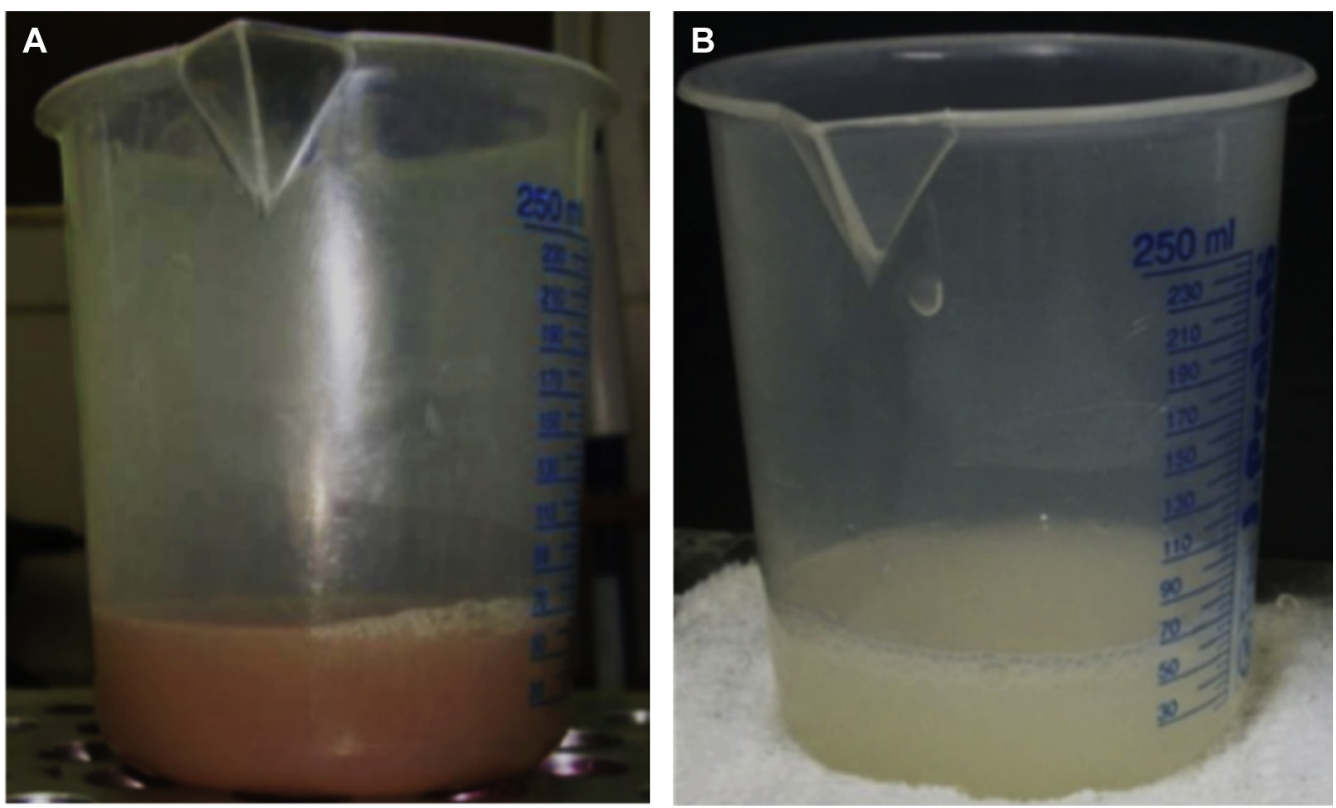

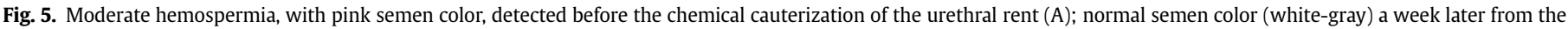
end of treatment (B).

was discarded. The treatment of $4 \%$ Policresulen was therefore administered, totaling four applications with an interval of 24 hours between each (Fig. 6B). During the treatment process, the horse housed in a stall used to masturbate with a high frequency during the day, when mares were transitioning to nearby stalls and even without any environment stimulus. Due to frequent sexual stimulation, the urethral rent did not completely heal, and bleeding continued during the period of excitation. Thus, the topical treatment with $4 \%$ Policresulen was prolonged for three more applications every 24 hours. As a consequence of the prolonged treatment, an inflammatory process of the penile urethra (urethritis) (Fig. 6C) was diagnosed by a new endoscopy, which revealed serohemorrhagic secretion, fibrin, and hyperemia. The examination of the stallion revealed clinical signs of discomfort, such as frequent penis exposure and frequent urination in small quantities. Systemic antibiotic therapy (Ceftiofur Sodium, TopCef-2 $\mathrm{mg} / \mathrm{kg}$, BID) for 7 days and nonsteroidal anti-inflammatory drugs (Flunixin Meglumine, Banamine-1.1 mg/kg, SID) were therefore used for the treatment of urethritis. In addition, the stallion was restricted to a stall and limited from the visual contact with females. About 20 days after the end of topical treatment, an additional urethroscopy found the penile urethra to be normal. In addition, semen was collected and found to be a normal white-gray color. Posttreatment sperm kinetic evaluation revealed total motility of $65 \%$, progressive motility of $30 \%$, and percentage of rapid sperm of $35 \%$.

\section{Discussion}

Policresulen has been used for many years in human medicine for chemical cauterization of the vaginal and cervical mucosa in women $[20,21]$. However, in veterinary medicine, there are only a few articles on its use [22-24]. Due to the demand for a less invasive, practical and low-cost technique, the use of Policresulen in this study was proven to be an excellent alternative for the treatment of urethral rents in stallions.
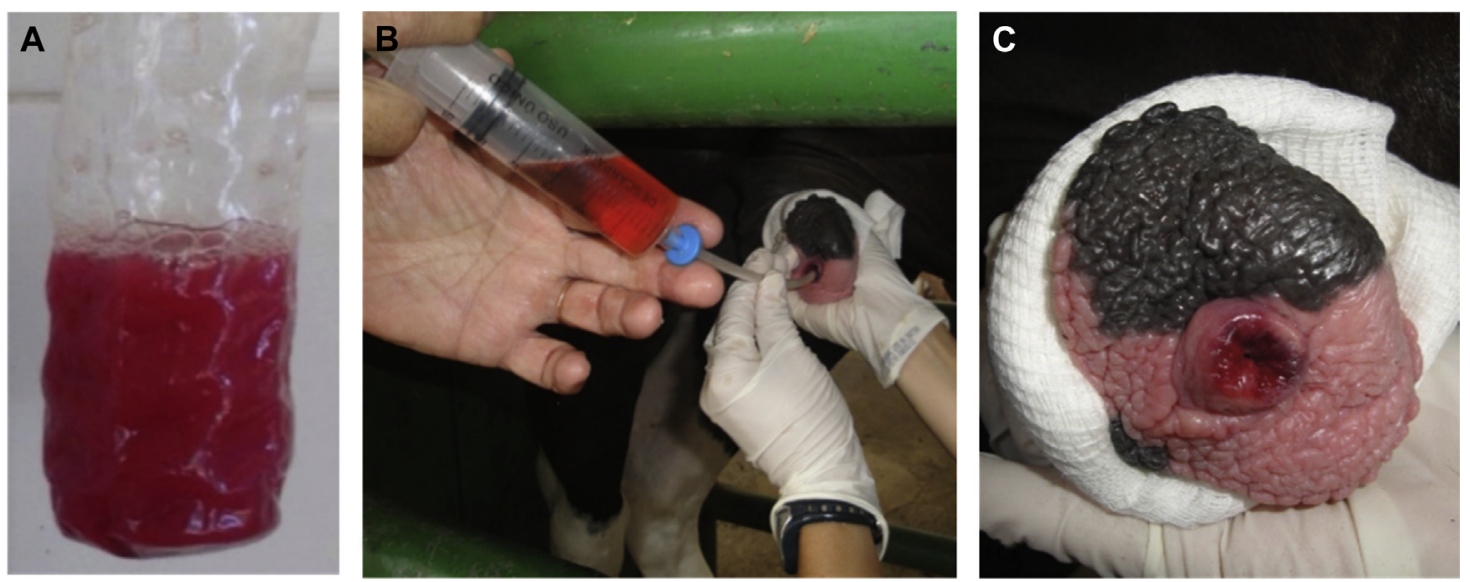

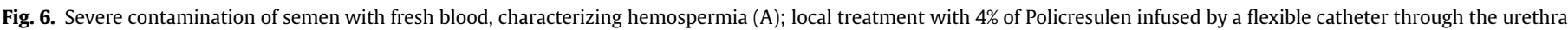
up to ischial arch (B); urethritis characterized by hyperemia of the urethral mucosa (C). 
When the topical treatment was performed with a 24-hour interval, totaling four applications, most of the animals presenting with total scarring of the urethral rent returned to normal parameters within a posttreatment period of 1 week, without exhibiting any inflammatory process of the urethral mucosa. However, when the treatment was prolonged, as in the case of stallions 1 and 4, symptoms of urethritis were found. These were slight in the first case; characterized by the discrete presence of $2 \%$ of inflammatory cells in the ejaculate but severe in case 4 , characterized by the notable discomfort shown by the animal and the presence of serohemorrhagic secretion, fibrin, and hyperemia.

Urethritis can occur as a consequence of prolonged treatment with the $4 \%$ Policresulen solution, probably because of the low $\mathrm{pH}$ of this solution and consequently mucosal irritation as well as an imbalance in the urethra microflora. This was evidenced in case 4 , in which the treatment for urethritis with antibiotic and anti-inflammatory therapy was required and resulted in recovery of the stallion without major consequences. However, in all cases presented, the chemical cauterization with Policresulen was efficient in the consolidation of the urethral rent and in the return of the stallions to reproductive activity within a week from the cessation of treatment, differing from the surgical procedures that requires at least 2-3 weeks for total recovery $[1,19]$. Also, no abnormalities were observed during the urethroscopy examination after the end of treatment, and all the stallions did not present remission of the episodes of hemospermia, demonstrating the feasibility and efficiency of this new treatment.

The reduction of fertility noted in some cases appeared to occur in stallions with severe hemospermia (cases 1 and 4). However, semen contamination with as low as $20 \%$ of whole blood is enough to cause decreased fertility $[15,16]$. Turner et al. [17] showed that up to $5 \%$ of blood contamination did not interfere with the fertility rates of fresh semen, but when this contamination increased to $50 \%$, fertility was entirely inhibited. The deleterious effect of blood on fertility may be related to the action of iron that composes hemoglobin. When free, iron acts directly on the sperm membranes causing peroxidative damage [25].

In only half of our cases, the presence of urethral rent was identified by urethroscopic examination. Despite a careful inspection of the entire penile and pelvic urethra is essential for an accurate diagnosis of urethral rent, the investigation and exclusion of other possible causes of hemospermia are fundamental to initiate the attempt of a treatment for this condition although based on a presumptive diagnosis. A lesion compatible with urethral fistula was detected in the region of the ischial arch in case 1 and in the penile urethra in case 4 . Although most lesions are present in the region of the ischial arch [1,3], they may also occur in additional locations along the duct as seen in the present study. Inspection of the vesicular glands is also a fundamental procedure to exclude the possibility of seminal vesiculitis in cases of hemospermia because the bleeding, in this case, results from an infectious process that requires local or systemic treatment with antibiotics $[6,7,26]$ and would not be solved with an infusion of a cauterizing agent intraurethral.

Sexual rest is essential for the complete healing of the urethral rent during the chemical cauterization of the lesion. This management includes the cessation of semen collection for either artificial insemination or for natural coverings, the inhibition of any excitatory stimulus to the animal (olfactory, auditory, or physical), such as the presence of females in nearby paddocks or stalls, and keeping the animal busy with other activities. The excess of spontaneous erection and masturbation impairs the complete healing of the urethral rent, as observed in case 4 [27].

\section{Conclusion}

Topical treatment with $4 \%$ Policresulen solution has been shown to be efficient in the chemical cauterization of urethral rent in stallions, constituting a less expensive and safe treatment than popular surgical methods, which are more invasive and require a longer recovery time.

The differential diagnosis for seminal vesiculitis is fundamental for a correct therapeutic approach because the exact detection of the rent site is difficult to determine by urethroscopy.

Sexual rest is an essential management in association with this therapeutic method because frequent sexual stimulation generates new bleeding, causing difficulty in healing.

In addition, the treatment should not exceed 4 days of topical application of the drug solution because low $\mathrm{pH}$ of the treatment can alter the microflora of the duct and cause an inflammatory process within the urethra.

\section{References}

[1] Schumacher J, Varner DD, Schmitz DG, Blanchard TL. Urethral defects in geldings with hematuria and stallions with hemospermia. Vet Surg 1995;24: 250-4.

[2] Schumacher J. Hematuria and pigmenturia of horses. Vet Clin North Am Equine Pract 2007;23:655-75.

[3] Taintor J, Schumacher J, Purohit R, DeGraves F, Sartin E. Comparison of pressure within the corpus spongiosum penis during urination between geldings and stallions. Equine Vet J 2004;36:362-4.

[4] Ball BA. Diagnostic methods for evaluation of stallion subfertility: a review. J Equine Vet Sci 2008;28:650-5.

[5] Glass KG, Arnold CE, Varner DD, Chaffin MK, Schumacher J. Signalment, clinical features, and outcome for male horses with urethral rents following perineal urethrotomy or corpus spongiotomy: 33 cases (1989-2013). J Am Vet Med Assoc 2016;249:1421-7.

[6] Blanchard TL, Varner DD, Hurtgen JP, Love CC, Cummings MR, Strezmienski PJ, Benson C, Kenney RM. Bilateral seminal vesiculitis and ampullitis in a stallion. J Am Vet Med Assoc 1988;192:525-6.

[7] Blanchard TL, Woods JA, Brinsko SP, Varner DD, Boothe DM. Theriogenology question of the month. Treatment options for erosive seminal vesiculitis caused by Acinetobacter calcoaceticus. J Am Vet Med Assoc 2002;15:221-6.

[8] Voss JL, Pickett BW. Diagnosis and treatment of haemospermia in the stallion. J Reprod Fertil Suppl 1975;23:151-4.

[9] Bedford SJ, McDonnell SM, Tulleners E, King D, Habecker P. Squamous cell carcinoma of the urethral process in a horse with hemospermia and selfmutilation behavior. J Am Vet Med Assoc 2000;216:551-3.

[10] McKinnon AO, Voss JL, Trotter GW, Picket BW, Shideler RK, Squires EL. Hemospermia of 176 the stallion. Equine Prac 1988;10:17-23.

[11] Pozor M, et al. Midline cysts of colliculus seminalis causing ejaculatory problems in stallions. J Equine Vet Sci 2011;31:722-31.

[12] Pearson LK, Campbell AJ, Tibary A. How to diagnose and treat hemospermia: a review and case series. Proc Am Assoc Equine Pract 2013:59:40-50.

[13] Lloyd KC, Wheat JD, Ryan AM, Matthews M. Ulceration in the proximal portion of the urethra as a cause of hematuria in horses: four cases (19781985). J Am Vet Med Assoc 1989;194:1324-6.

[14] Beckett SD, Walker DF, Hudson RS, Reynolds TM, Purohit RC. Corpus spongiosum penis pressure and penile muscle activity in the stallion during coitus. Am J Vet Res 1975;36:431-3.

[15] Moller G, Azevedo LR, Trein CR, Neves AP, Garbade P, Mattos RC. Effects of hemospermia on seminal quality. Anim Reprod Sci 2005;89:264-7.

[16] Voss J, Wotowey J. Hemospermia, in Proceedings. Am. Assoc. Equine Pract 1972;18:103-12.

[17] Turner CE, Walbornn SR, Blanchard TL, Varner DD, Brinsko SP, LaCaze KA, Teague SR, Love CC. The effect of two levels of hemospermia on stallion fertility. Theriogenology 2016;86:1399-402.

[18] Sullins KE, Bertone JJ, Voss JL, Pederson SJ. Treatment of hemospermia in stallions: a discussion of 18 cases. Compend Contin Educ Pract Vet 1988;10: 1396-403.

[19] Madron M, Schleining J, Caston S, Reinertson E, Evans L. Laser treatment of urethral defects in geldings and stallions used as the primary treatment or in combination with a temporary subischial incision: Eight cases (2003-2011). Equine Vet Educ 2013;25:368-73.

[20] Lomando SR, Ferrary MB, Ferrari A. Substâncias coadjuvantes no pós-cautério: Estudo comparativo. Rev Bras Med 1983;40:172-5.

[21] Shivanna BS, Shivanna L, Kulkarni P. Comparative study of efficacy of cryosurgery and Albothyl ${ }^{\mathbb{R}}$ solution in the management of cervical erosion in a rural hospital. J Dental Med Sci 2014:13:106-9.

[22] Ali A, Al-Sobayil FA, Al-Hawas A. Evaluating the effectiveness of different treatments of uterine infections in female camels (Camelus dromedarius). Theriogenology 2010;74:40-4. 
[23] Ali A, Al-Sobayil FA, Hassanein KM, Al-Hawas A. Ovarian hydrobursitis in female camels (Camelus dromedarius): the role of Chlamydophila abortus and a trial for medical treatment. Theriogenology 2012;77: $1754-8$.

[24] Janßen S, Wunderlich C, Heppelmann M, Palme R, Starke A, Kehler W, Steiner A, Rizk A, Meyer U, Daenicke S, Rehage J. Pilot study on hormonal, metabolic, and behavioral stress response to treatment of claw horn lesions in acutely lame dairy cows. J Dairy Sci 2016;99:7481-8.
[25] Rijsselaere T, Van Soom A, Maes D, De Kruif A. Effect of centrifugation on in vitro survival of fresh diluted canine spermatozoa. Theriogenology 2004;57:1669-81.

[26] Pinto MR, Neild DM, Benegas D, Vieyra DH, Miragaya MH. Successful treatment of seminal vesiculitis with Imipenem-Cilastatin in a stallion. J Equine Vet Sci 2014;34:544-8.

[27] McDonnell SM, Henry M, Bristol F. Spontaneous erection and masturbation in equids. J Reprod Fertil Suppl 1991;44:664-5. 